\title{
THE INFLUENCE OF THE LOAD ON THE HARDNESS
}

\section{Jozef Petrík, Pavol Palfy}

Technical University of Košice, Faculty of Metallurgy, Dept. of Integrated Management, Letná 9, 04001 Košice, Slovakia (囚jozef.petrik@tuke.sk)

\begin{abstract}
The objective of the submitted paper is to analyze the influence of the load on the calibration of micro-hardness and hardness testers. The results were validated by Measurement Systems Analysis (MSA), Analysis of Variance (ANOVA) and Z-score. The relationship between the load and micro-hardness in calibration of microhardness testers cannot be explained by Kick's Law (Meyer's index "n" is different from 2). The conditions of Kick's Law are satisfied at macro-hardness calibration, the values of " $n$ " are close to 2, regardless of the applied load. The apparent micro-hardness increases with the increase of the load up to $30 \mathrm{~g}$; the reverse indentation size effect (ISE) behavior is typical for this interval of the loads. The influence of the load on the measured microhardness is statistically significant for majority of calibrations.
\end{abstract}

Keywords: hardness, load, calibration, uncertainty, MSA

(C) 2011 Polish Academy of Sciences. All rights reserved

\section{Introduction}

The Vickers test is the standard method for measuring the hardness of metals, particularly those with extremely hard surfaces: the surface is subjected to a standard pressure for a standard length of time by means of a pyramid-shaped diamond with a vertex angle of $136^{\circ}$. The diagonal of the resulting indentation is measured under a microscope. The Vickers testing method is the most accurate and sensitive hardness test method. It is unsuitable for inhomogeneous and coarse-grained materials. A thoroughly prepared surface is required before the test. The micro-hardness measurement, identical to the Vickers method, is frequently used for measurement of small items or thin layers hardness and identification of individual phases in metallography. The micro-hardness tester is usually a part of an optical microscope. Like in any test of mechanical properties, there is the obvious requirement for reliability of measurement results, which is unthinkable without sufficient quality of the measurement process [1].

The advantage of the Vickers test is macro-hardness independence (by definition) on the test force, because the indentations with various diagonals are geometrically similar. The stability of macro-hardness despite of force change is described by Kick's Law [2]. The measured micro-hardness of solids, on the other hand, depends on the applied indentation test load. This phenomenon, known as the indentation size effect (ISE), usually involves a decrease in the apparent micro-hardness with increasing applied test load, i.e., with increasing indentation size [3].

The aim of the submitted work was to study the results of indirect calibration of the micro-hardness and macro-hardness testers depending on the applied load (ranges $10 \mathrm{~g} \div 100 \mathrm{~g}$ and $5 \mathrm{~kg} \div 120 \mathrm{~kg}$ ). The results were evaluated by Z-score, one factor analysis of variance (ANOVA) and Measurement Systems Analysis (MSA). 


\section{The equipment and CRMs}

The Vickers testers are not legal measuring instruments (Act No. 142/2000 Z.z.). Their metrological confirmation is limited to direct or indirect calibration. Metrological confirmation shall be designed and implemented to ensure that the metrological characteristics of the measuring equipment satisfy the metrological requirements for the measurement process [4].

The micro-hardness tester Hanemann, type Mod D32, part of optical microscope NEOPHOT 32 (magnification of indentations measuring device $480 \times$ ) and the hardness tester HPO 250 (magnification 70×) were calibrated. According to the direct calibration (V/10) the function and metrological characteristics of the HPO 250 tester satisfy the requirements of the standard [5].

Certified reference materials (CRM) in the form of a hardness reference block were used as standards for calibration. Their specified hardness $\mathrm{H}_{\mathrm{c}}$ and the standard uncertainty $\mathrm{u}_{\mathrm{CRM}}$ are presented in Table 1. The CRMs No. 1 and 5 were used for calibration of both testers.

Table 1. The characteristics of CRMs.

\begin{tabular}{|c|l|l|c|}
\hline No. & \multicolumn{1}{|c|}{$\mathrm{H}_{\mathrm{c}}$ of CRM } & \multicolumn{1}{|c|}{$\mathrm{u}_{\mathrm{CRM}}$} & year of calibration \\
\hline 1 & $194 \mathrm{HV} 10$ & $1.55 \mathrm{HV} 10$ & 2007 \\
\hline 2 & $195 \mathrm{HV} 0.05$ & $4 \mathrm{HV} 0.05$ & 2007 \\
\hline 3 & $242 \mathrm{HV} 0.05$ & $5.4 \mathrm{HV} 0.05$ & 2008 \\
\hline 4 & $259 \mathrm{HV} 10$ & $1.55 \mathrm{HV} 10$ & 2008 \\
\hline 5 & $482 \mathrm{HV} 10$ & $3.15 \mathrm{HV} 10$ & 2008 \\
\hline 6 & $519 \mathrm{HV} 0.05$ & $6.75 \mathrm{HV} 0.05$ & 2008 \\
\hline
\end{tabular}

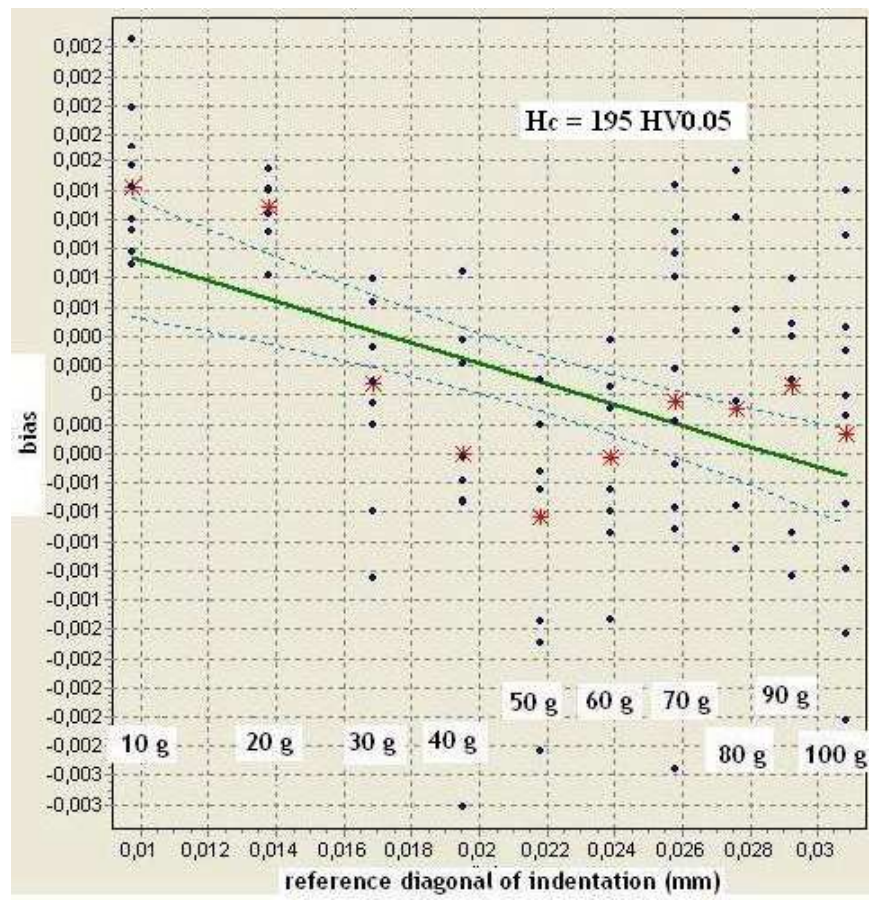

Fig. 1. The linearity of micro-hardness tester, CRM No. 2.

The linearity of testers was evaluated by CAQ Palstat software. The reference lengths of diagonals (calculated for the used CRM and load), were compared with measured values. The bias of linearity is satisfactory only for loads 70,80 and $100 \mathrm{~g}$ during the calibration of the 
micro-hardness tester using CRM No. 2 (Fig. 1). The bias of linearity during the calibration of the macro-hardness tester using CRM No. 1 is suitable for all loads except for $10 \mathrm{~kg}$ and using CRM No. 5 is suitable for all loads except for 10,20 and $30 \mathrm{~kg}$.

\section{Experimental}

The calibration of both testers was carried out by two approximately equally skilled researchers (A, B) with five indentations at each CRM and each load/test force $\mathrm{F}$ (Table 2 according to [6]) with an application time of 15 seconds. The hardness, measured in individual calibrations is on Fig. 2a for operator A and Fig. $2 b$ for researcher B. The measured micro-hardness is significantly low when the loads $10 \mathrm{~g}$ or $20 \mathrm{~g}$ were applied. The hardness is relatively stable at the loads above $30 \mathrm{~g}$, or it moderately decreases with increasing load. The load sensitivity increased with increasing specified hardness of the used CRM.
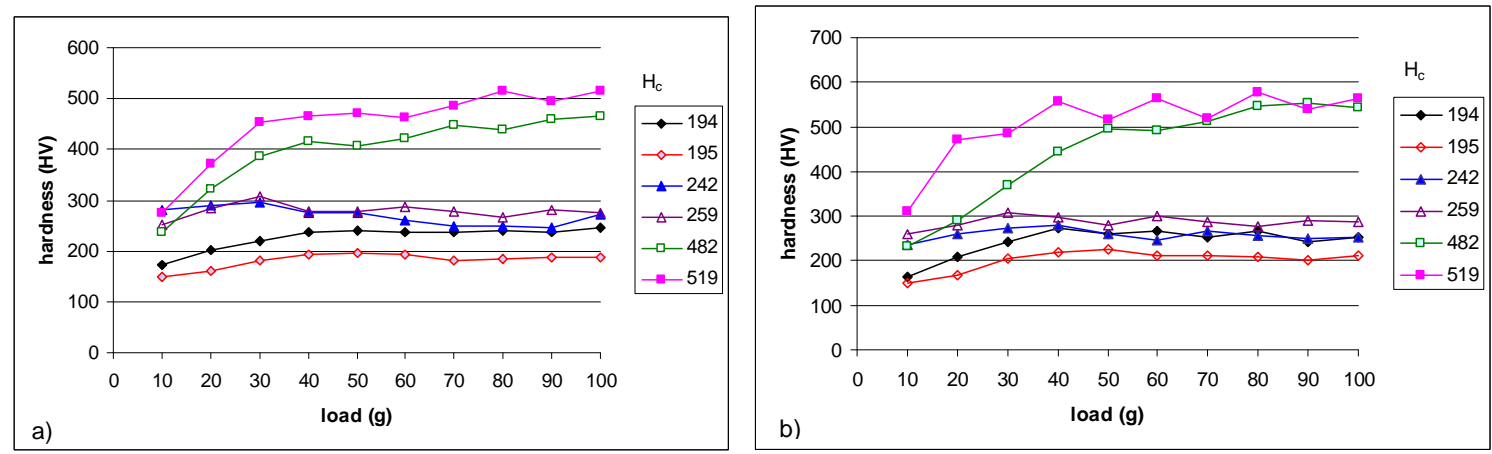

Fig. 2. The relationship between CRM, load and micro-hardness, a) researcher A, b) researcher B.

Table 2. The loads in Newtons used for measurement of the micro-hardness and hardness tests.

\begin{tabular}{|c|c|c|c|c|c|c|c|c|}
\hline $\mathrm{g}$ & 10 & 20 & 30 & 40 & 50 & 60 & 70 & 80 \\
\hline $\mathrm{N}$ & 0.09807 & 0.1961 & 0.2942 & 0.39228 & 0.4903 & 0.58842 & 0.68649 & 0.78456 \\
\hline $\mathrm{g}$ & 90 & 100 & 5000 & 10000 & 15000 & 15620 & 20000 & 30000 \\
\hline $\mathrm{N}$ & 0.8826 & 0.9807 & 49.03 & 98.07 & 147.11 & 153.2 & 196.1 & 294.2 \\
\hline $\mathrm{g}$ & 31250 & 40000 & 50000 & 60000 & 62500 & 100000 & 120000 & \\
\hline $\mathrm{N}$ & 306.5 & 392.28 & 490.3 & 588.42 & 612.9 & 980.7 & 1176.84 & \\
\hline
\end{tabular}

Table 3. No. of calibration, load, $\mathrm{H}_{\mathrm{c}}$ of CRM, p-value (normality), average hardness $\left(\bar{H}_{\mathrm{AB}}\right)$, standard deviation $\mathrm{s}_{\mathrm{H}}, \mathrm{p}$-values of ANOVA.

\begin{tabular}{|c|c|c|c|c|c|c|c|c|c|}
\hline No. & load $\mathrm{F}$ & $\mathrm{H}_{\mathrm{c}}$ & $\mathrm{p}$-norm. & $\bar{H}_{\mathrm{AB}}$ & $\mathrm{s}_{\mathrm{H}}$ & $\mathrm{p}_{\text {rel }}$ & $\mathrm{p}_{\text {rel }}$ & $\mathrm{p}_{\text {rel }}$ & $\mathrm{p} \mathrm{HV}$ \\
\hline 1 & $10-100 \mathrm{~g}$ & $195 \mathrm{HV} 0.05$ & 0.0970 & 191 & 23.861 & 0.13493 & 0.04031 & 0.19266 & 0.04643 \\
\hline 2 & $10-100 \mathrm{~g}$ & $194 \mathrm{HV} 10$ & 0.0 & 235 & 30.275 & 0.21448 & 0.09222 & 0.29751 & 0.00230 \\
\hline 3 & $5-60 \mathrm{~kg}$ & $194 \mathrm{HV} 10$ & 0.1149 & 194 & 2.115 & 0.04186 & 0.00396 & 0.16562 & 0.00394 \\
\hline 4 & $10-100 \mathrm{~g}$ & $242 \mathrm{HV} 0.05$ & 0.0287 & 264 & 20.329 & 0.21086 & 0.24303 & 0.07789 & 0.37770 \\
\hline 5 & $10-100 \mathrm{~g}$ & $259 \mathrm{HV} 10$ & 0.0807 & 282 & 17.830 & 0.01414 & 0.00162 & 0.46603 & 0.00161 \\
\hline 6 & $10-100 \mathrm{~g}$ & $519 \mathrm{HV} 0.05$ & 0.0 & 481 & 81.547 & 0.00399 & 0.00154 & 0.90398 & 0.00807 \\
\hline 7 & $10-100 \mathrm{~g}$ & $482 \mathrm{HV} 10$ & 0.0033 & 422 & 95.361 & 0.00007 & 0.00006 & 0.63883 & 0.00239 \\
\hline 8 & $5-120 \mathrm{~kg}$ & $482 \mathrm{HV} 10$ & 0.0 & 480 & 10.475 & 0.00040 & 0.00020 & 0.07140 & 0.00010 \\
\hline
\end{tabular}

The normality and the outliers were evaluated for files, involving all calibrations with one CRM by both researchers at all loads ( $\mathrm{n}=100$ indentations). The doubts concerning the normality of distribution will be finally dissolved if the procedure for the tests of the concordance between the method error distribution and the theoretical distribution is applied 
[7]. The normality was determined by Freeware Process Capability Calculator software, using the Anderson-Darling test ( $\mathrm{p} \geq 0.05$ for file with normal distribution). The standard methods of MSA assume normal probability distribution. If normality is not confirmed, the error of the measurement system is overestimated [8]. According to Table 3, the normality was confirmed for $33 \%$ of micro-hardness files and for $50 \%$ of macro-hardness files. Grubbs' test (significance level $\alpha=0.05$ ) was used for detection of statistical outliers. The outliers do not occur, the measurement process is not affected by special disturbances (e.g. gross errors).
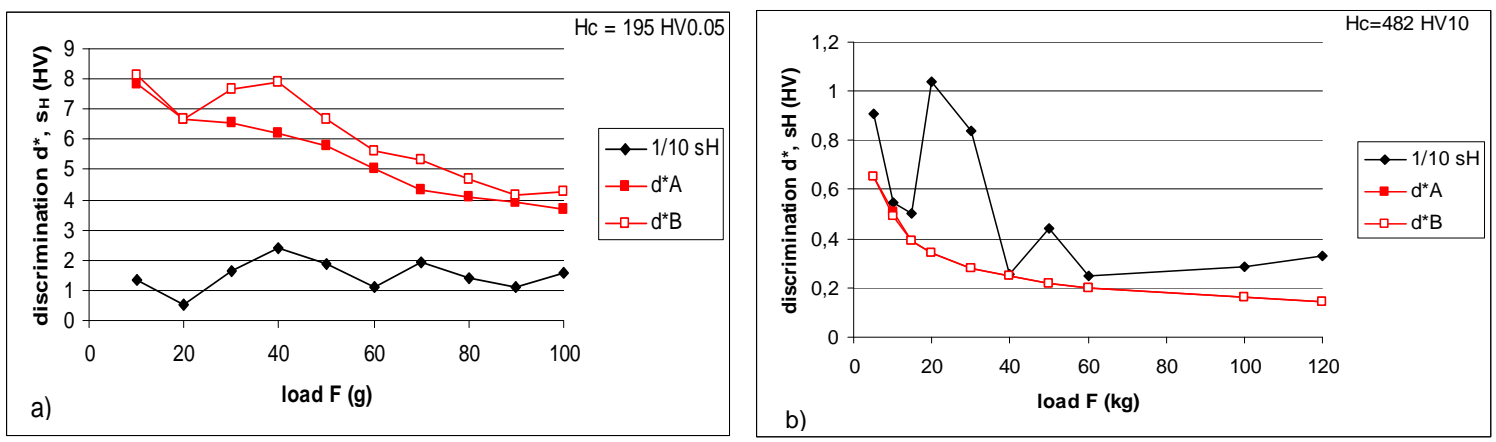

Fig. 3. The relationship between discrimination $d^{*}$ and standard deviation $s_{H}$ for a) micro-hardness and for $b$ ) macro-hardness, the line $\mathrm{d}^{*} \mathrm{~B}$ overlaps $\mathrm{d}^{*} \mathrm{~A}$.

A general rule of thumb is that the effective resolution - discrimination $\mathrm{d}^{*}$ (the value of the smallest scale division, the step of the drum of the indentations measuring device), as compared with the process variation expressed in standard deviation $\mathrm{s}_{\mathrm{H}}$ (Table 3), both figured in HV units, ought to be at most one-tenth [9].

$$
d^{*}=\left|\frac{H V_{5}-H V_{1}}{d_{5}-d_{1}}\right|,
$$

where $d_{1}$ and $d_{5}$ are mean values of length of two diagonals of "hardest" $\left(\mathrm{HV}_{5}\right)$ and "softest" $\left(\mathrm{HV}_{1}\right)$ of 5 indentations. All measurements of micro-hardness do not satisfy the requirement of effective resolution. Fig. 3a exemplifies "insufficient" relationship for micro-hardness, CRM No. 2 and Fig. 3b "sufficient" relationship for macro-hardness, CRM No. 5. Increasing the load and hardness improves the relationship between $\mathrm{d}^{*}$ and $\mathrm{s}_{\mathrm{H}}$.
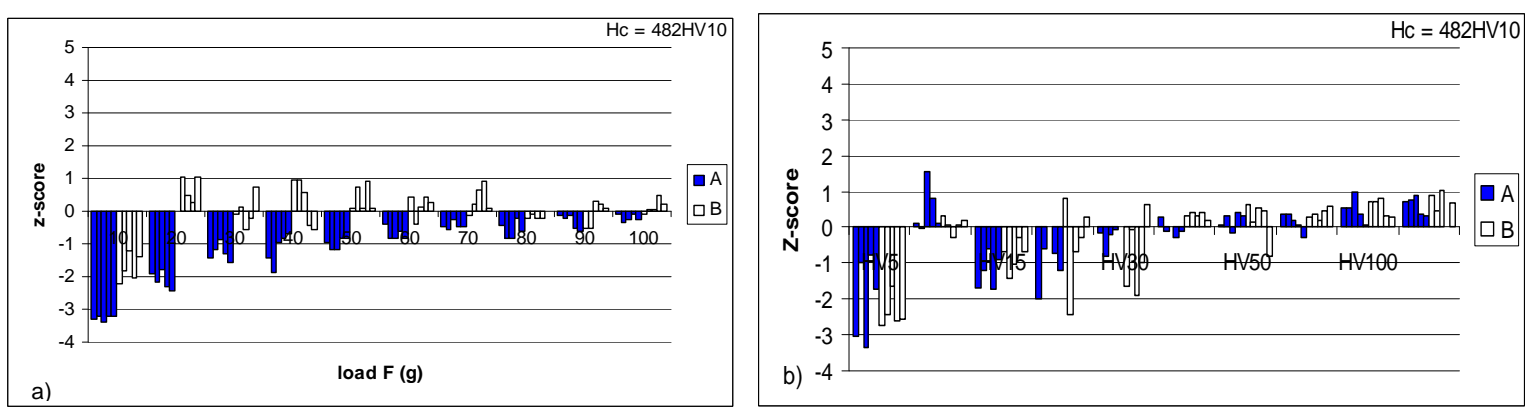

Fig. 4. Z-score, a) micro-hardness, b) macro-hardness.

\section{Z-score}

The Z-score graphical method for the visualization of results is routinely applied in interlaboratory comparisons. 


$$
z_{i}=\frac{x_{i}-\bar{x}}{s},
$$

$x_{i}$ is the hardness at one indentation on CRM, measured at individual load by one researcher, $\bar{x}$ is average hardness ( $\bar{H}_{\mathrm{A}+\mathrm{B}}$, Tab. 3) and „," “is standard deviation of the file ( $\left.\mathrm{s}_{\mathrm{H}}, \mathrm{Tab} .3\right)$. The results with $\left|z_{i}\right| \leq 2$ are satisfactory and $\left|z_{i}\right| \geq 3$ are unsatisfactory [9]. The values of Zscore are satisfactory or conditionally satisfactory for most of micro-hardness tester calibrations. Unsatisfactory values are typical for low loads, $10 \mathrm{~g}$ or $20 \mathrm{~g}$, for example Fig. 4a (No. 7; $\mathrm{H}_{\mathrm{c}}=482 \mathrm{HV} 10$ ). The dependence of the value of Z-score of macro-hardness tester calibration, for example Fig. $4 \mathrm{~b}\left(\right.$ No. $\left.8, \mathrm{H}_{\mathrm{c}}=482 \mathrm{HV} 10\right)$ on the load is smaller than that of micro-hardness, but it is not completely eliminated. The values of $\mathrm{Z}$-score for micro-hardness decreases with the increase of the hardness of CRMs with exception for calibration No. 2.

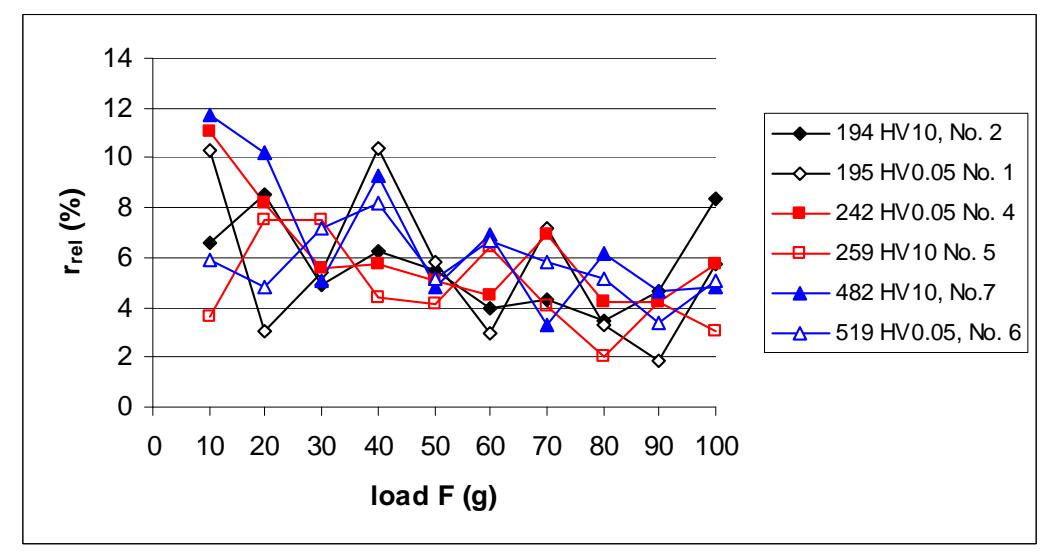

Fig. 5. The relationship between load $\mathrm{F}$ and $\mathrm{r}_{\text {rel }}$.

\section{The repeatability, relative maximum error and uncertainty}

The mean diagonal:

$$
\bar{d}=\frac{d_{1}+d_{2}+d_{3}+d_{4}+d_{5}}{5} .
$$

The repeatability of tester $r_{\text {rel }}$ is calculated:

$$
r_{r e l}=100 \times \frac{d_{5}-d_{1}}{\bar{d}} \%,
$$

$d_{5}$ is the average diagonal length of the indentation with the longest and $d_{1}$ one with the shortest diagonals.

The average measured hardness of CRM: $\bar{H}=\frac{H_{1}+H_{2}+H_{3}+H_{4}+H_{5}}{5}$.

The maximum permissible error at specific conditions of calibration is:

$$
E=\bar{H}-H_{c} \text {. }
$$

Maximum relative error:

$$
E_{r e l}=100 \times \frac{\bar{H}-H_{c}}{H_{c}},
$$

$\bar{H}=\bar{H}_{A}$ or $\bar{H}_{B}$ (average of researcher $\mathrm{A}$ or $\mathrm{B}$ ). The maximum value of repeatability and error of the tester are cited in [5]. The average values of $r_{\text {rel }}$ (Fig. 5) and $E_{\text {rel }}$ (Fig. 6) moderately decrease with increasing load.

The uncertainty of indirect calibration is calculated: 


$$
\mathrm{u}_{\mathrm{HTM}}=\sqrt{u_{C R M}^{2}+u_{C R M-D}^{2}+u_{H}^{2}+u_{m s}^{2}} .
$$

The standard uncertainty of the CRM used $\left(\mathrm{u}_{\mathrm{CRM}}\right)$ is shown in Table 1 . The uncertainty resulting from drift of CRM hardness $\mathrm{u}_{\mathrm{CRM}}$ was dismissed. It is impossible to determine this value, because used CRMs were calibrated only once. Standard uncertainty of hardness tester:

$$
\mathrm{u}_{\mathrm{H}}=\frac{t \times s_{H}}{\sqrt{n}}
$$

$\mathrm{s}_{\mathrm{H}}$ is standard deviation of the testing of CRM (standard deviation of the results of indirect calibration), Student's factor for $n=5$ (trials - repeated measurements of one researcher) is $\mathrm{t}=1.15, \alpha=0.317[6]$.

The uncertainty $\mathrm{u}_{\mathrm{ms}}$ rises from inaccuracy of the device, measuring the diagonals of indentations.

$$
\begin{gathered}
u_{m s}=\frac{\bar{H} \delta_{m s}}{d \sqrt{3}} ; \\
d=\sqrt{0.1891 \frac{F}{H_{c}}},
\end{gathered}
$$

$\mathrm{F}$ is the relevant test load $(\mathrm{N})$ and $\mathrm{H}_{\mathrm{c}}$ is the specified hardness of CRM. The value of discrimination $\delta_{m s}=0.001 \mathrm{~mm}$ for HPO 250 and $\delta_{m s}=0.000313 \mathrm{~mm}$ for Hanemann (note: the abovementioned discrimination $\mathrm{d}^{*}$ is in $\mathrm{HV}$ units).

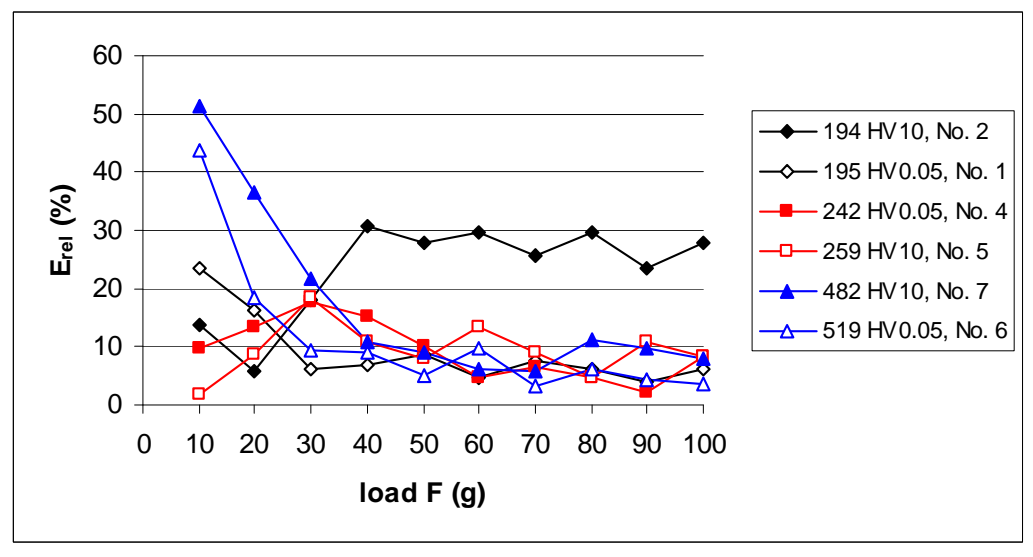

Fig. 6. The relationship between load $\mathrm{F}$ and $\mathrm{E}_{\text {rel }}$.

The error of calibration:

$$
\bar{b}=\bar{H}-H_{c}=E .
$$

The expanded uncertainty (coverage factor $\mathrm{k}=2$ ): $U_{\text {HTM }}=k \cdot u_{\text {HTM }}$.

The maximum permissible error of the tester, including the measurement uncertainty:

$$
\Delta H_{H T M \max }=U_{H T M}+|\bar{b}| \text {. }
$$

Relative maximum permissible error of the tester (relative expanded uncertainty):

$$
U_{\text {rel }}=\frac{\Delta U_{H T M \max }}{\bar{H}} \times 100 \% \text {. }
$$

The value of relative expanded uncertainty $U_{\text {rel }}$ for micro-hardness decreases with the increase of the load and hardness of CRM is shown in Fig. 7a (average value of researcher A and B). For CRMs with lower hardness, the relationship between uncertainty and the load is weak. The values of uncertainty of macro-hardness have the highest value at a load of $5 \mathrm{~kg}$, 
another increase of load results in its stabilization, are shown in Fig. 7b (average value of researchers $\mathrm{A}$ and $\mathrm{B}$ ).

It is necessary to remember that indirect calibration of micro-hardness testers is not a routinely practiced process unlike with the macro-hardness testers. Small dimensions of indentations, especially with irregular shape are measured with difficulty. Small difference in reading of dimension of diagonals has a significant effect on the value of micro-hardness and makes the influence of individuality and skill of researcher possible. Unsatisfactory calibration results could be improved by greater magnification (with demands on the quality of the metallic surface), selection of researchers (their competence, including education, preparation and experience), higher quality of CRM (with low uncertainty), strict observance of operating instructions (standardized methods) and the conditions of the environment. It is possible that a high value of uncertainty of calibration is a result of low capability (high value of \%GRR) [10]. The uncertainties and coverage factors could be calculated using other methods $[11,12,13]$ as well.
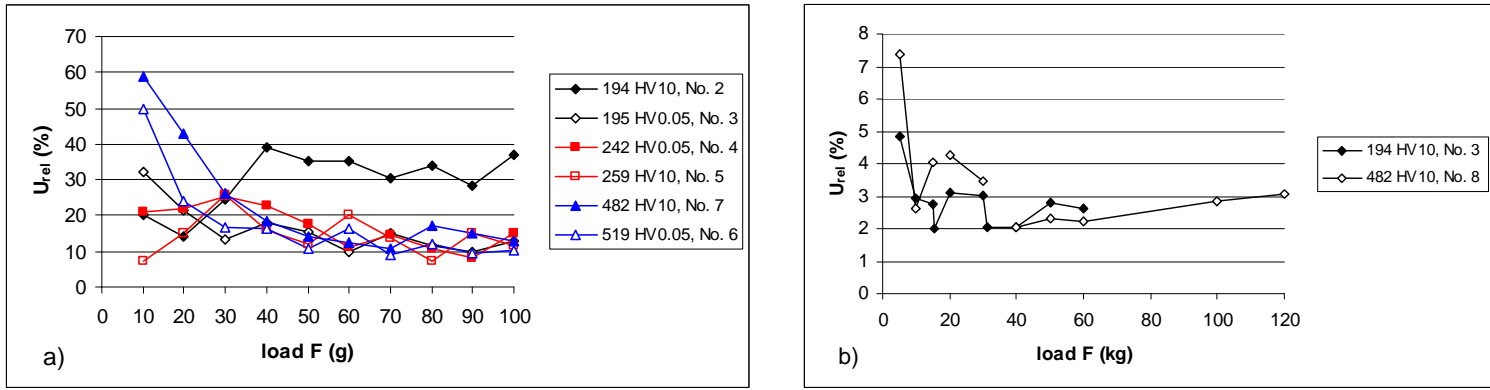

Fig. 7. The relationship between load $\mathrm{F}$ and $\mathrm{U}_{\text {rel }}$ for a) micro-hardness and for b) macro-hardness.

One-factor analysis of variance (ANOVA) was used for evaluation of the influence of load on the $U_{\text {rel }}, E_{\text {rel }}, r_{\text {rel }}$ and hardness. The $p$ values are shown in Table 3 . The value $p<0.05$ is for statistically significant influence of the load on monitored quantity.

The load affects the values of $U_{\text {rel }}$ and $E_{\text {rel }}$ statistically significantly in micro-hardness calibrations with hard CRMs and in all macro-hardness calibrations. On the other hand, the values of $r_{\text {rel }}$ are not affected. Except for one example, the micro-hardness is affected by the load.

\section{Measurement systems analysis (MSA)}

Measurement systems analysis is an experimental and mathematical method of determining how much the variation within the measurement process contributes to overall process variability. The measurement process, running in a capable measurement system (which consists of measurement equipment, samples, environment, method, researchers ...) is capable as well.

Table 4. The capability indices.

\begin{tabular}{|c|c|c|c|c|c|c|c|}
\hline No. & $\% \mathrm{R}$ & $\% \mathrm{X}$ & $\% \mathrm{EV}$ & $\% \mathrm{AV}$ & $\% \mathrm{PV}$ & \%GRR & ndc \\
\hline 1 & 5 & 55 & 31.7 & 54.6 & 75.1 & 66.0 & 1.604 \\
\hline 2 & 0 & 55 & 35.9 & 35.4 & 86.4 & 50.4 & 2.417 \\
\hline 3 & 0 & 6.6 & 70.1 & 0.0 & 71.3 & 70.1 & 1.404 \\
\hline 4 & 0 & 30 & 68.1 & 39.0 & 78.9 & 78.9 & 1.098 \\
\hline 5 & 5 & 30 & 56.1 & 23.8 & 60.9 & 60.9 & 1.837 \\
\hline 6 & 0 & 55 & 25.1 & 45.2 & 51.7 & 51.7 & 2.334 \\
\hline 7 & 0 & 70 & 25.0 & 35.4 & 43.4 & 43.4 & 2.930 \\
\hline 8 & 15 & 40 & 49.8 & 0.0 & 49.8 & 49.8 & 2.455 \\
\hline
\end{tabular}


The computation of the hardness measurement system capability according to the GRR method of MSA (analysis of repeatability and reproducibility) was carried out in accordance with [8]. The Palstat CAQ software with significance level $\alpha=0.01$ and confidence level $\alpha=0.01(5.15 \sigma)$ was used for calculation. The values of capability indices are presented in Table 4.

The measurement system ought to be under statistical control before capability is assessed. The process is under control, if all ranges are between control limits of the control chart. The outside ranges were found at three files (Tab. 4. column \%R).

The area within the control limits of the X-bar control chart represents measurement sensitivity ("noise"). One half or more of the averages should fall outside the control limits. If the data show this pattern, then the measurement system should be adequate to detect variation between the values of hardness, affected by levels of the applied load F. If the opposite was the case, then the measurement system would lack the adequate effective resolution. The fact that only $50 \%$ of files have sufficient sensitivity (Tab. 4, column \%X) relates to insufficient discrimination $\mathrm{d}^{*}$.

The $\% \mathrm{EV}$ index represents the cumulative effect of measurement equipment, measuring method and environmental conditions on the variability. It is a function of average range of trials of all researchers.

The \% AV index represents the effect of researchers on the variability, for example their liability, responsibility and competence. It is a function of the maximum average researcher difference. A low value of the index proves good competence of all researchers. Higher (or unstable) value of index shows evidence of variable quality of their work.

The \%GRR index represents the process capability in practice. For acceptable measurement system \%GRR $<10 \%$, and $>30 \%$ for not acceptable. The analyzed measurement system and the process running in it are not acceptable - capable for all CRMs. It is possible that non-capability is typical for micro-, but also for macro-hardness measurement [14].

The $\% \mathrm{PV}$ is sensitive to variability of applied loads $\mathrm{F}$, it is a function of their range. The value of $\% \mathrm{PV}$ indirectly defines the suitability of equipment for a specific measurement. A value of \%PV above $99 \%$ has excessively accurate, above $90 \%$ suitable, above $70 \%$ satisfactory and above $50 \%$ inaccurate equipment.

The number of distinct categories ("ndc", based on Wheeler's discrimination ratio) is connected with the question of the resolution of measurement equipment. The "ndc" is greater than or equal to 5 for capable processes. Results with "ndc" values between 2-5 may be conditionally used for rough estimates. As can be seen in Table 4, the values of "ndc" are insufficient, eventually ( $50 \%$ ) may be used for rough estimates.

\section{Discussion}

The micro-hardness HV is calculated in VHN, using the standard formula:

$$
H V=\frac{A_{0} P}{d^{2}}
$$

when $\mathrm{P}$ is taken in $\mathrm{N}$ and $\mathrm{d}$ in $\mu \mathrm{m}$, then $\mathrm{A}_{0}=0.1891$ and hardness is in MPa, implying that $1 \mathrm{VHN}=9.8 \mathrm{MPa}$ [3]. It is well-known that the apparent micro-hardness of solids depends on the applied indentation test load. This phenomenon, known as the indentation size effect (ISE) usually involves a decrease in apparent micro-hardness with increasing applied test load F. In order to describe the normal ISE behavior of materials, several relationships between the applied indentation test load $\mathrm{F}$ and indentation diagonal length $d$ have been given in the literature. The simplest way to describe the ISE is Meyer's Law 


$$
\mathrm{P}=\mathrm{Ad}^{\mathrm{n}}
$$

where the exponent " $n$ ", the Meyer's index (number) is a measure of the ISE and $A$ is a constant.

Table 5 shows the values of Meyer's index " $n$ " and $\ln A$ (columns $n_{(A+B)}, \ln A_{(A+B)}$ ) as a slope (n) and an intercept ( $\ln \mathrm{A})$ of a straight line of the linear relationship between the applied load $(\ln \mathrm{P}(\mathrm{g}))$ and average diagonal of five indentations $(\ln \mathrm{d}(\mu \mathrm{m}))$. The parameter $\mathrm{A}$ is dependent on the relationship between the applied load and average diagonal of the indentations for tested material and on the characteristics of the equipment used (for example for heat treated cobalt alloy $\ln A=-1.806 \mathrm{~g} / \mu \mathrm{m}^{\mathrm{n}}$ obtained by a Hanemann tester and $\ln \mathrm{A}=-6.744 \mathrm{~g} / \mu \mathrm{m}^{\mathrm{n}}$ by a PMT-3 tester, respectively) [3].

Table 5. The indices of ISE for individual files, correlation coefficients $\mathrm{r}$ for relationship between $\ln \mathrm{d}$ and $\ln \mathrm{F}$ (joined results of $\mathrm{A}$ and $\mathrm{B}$ ).

\begin{tabular}{|c|c|c|c|c|c|c|c|c|}
\hline No. & 1 & 2 & 3 & 4 & 5 & 6 & 7 & 8 \\
\hline $\mathrm{n}_{\mathrm{A}+\mathrm{B}}$ & 2.2398 & 2.3348 & 2.0186 & 2.0631 & 2.0404 & 2.5141 & 2.9238 & 2.0304 \\
\hline $\ln \mathrm{A}_{\mathrm{A}+\mathrm{B}}$ & -3.1308 & -3.0621 & -2.3727 & -2.0529 & -1.9998 & -2.6997 & -3.9887 & -1.5302 \\
\hline $\mathrm{r}$ & 0.9915 & 0.9924 & 0.9995 & 0.9830 & 0.9977 & 0.9831 & 0.9809 & 0.9999 \\
\hline
\end{tabular}

When a very low load is used, the measured micro-hardness is usually high; with an increase in test load, the measured hardness decreases. Such a phenomenon is referred to as indentation size effect (ISE) with $n<2$. The ISE has been attributed to a number of causes which may be divided into two groups. The first group of causes includes experimental errors resulting from the measurement of the indentation size (for example the limitations of the resolution of the objective lens) and determination of the applied load [15]. The second group includes properties of the material under study. Among the latter are: work hardening during indentation, load to initiate plastic deformation, indentation elastic recovery, mixed elastic plastic deformation response of material, size of dislocation loops formed during indentation, strain gradients associated with dislocations, indentation edges acting as plastic hinges and indenter - specimen friction resistance coupled with elastic resistance of the specimen [3].

In contrast to the normal ISE, a reverse type of ISE is also known. The apparent microhardness increases with increasing applied test load and $n>2$. Reverse ISE has been explained in terms of the existence of a distorted zone near the crystal-medium interface, effects of vibration and indenter bluntness at low loads, the applied energy loss as a result of specimen chipping around the indentation and the generation of median or radial cracks during the indenter loading half-cycle. However, the phenomenon still remains poorly understood [16].

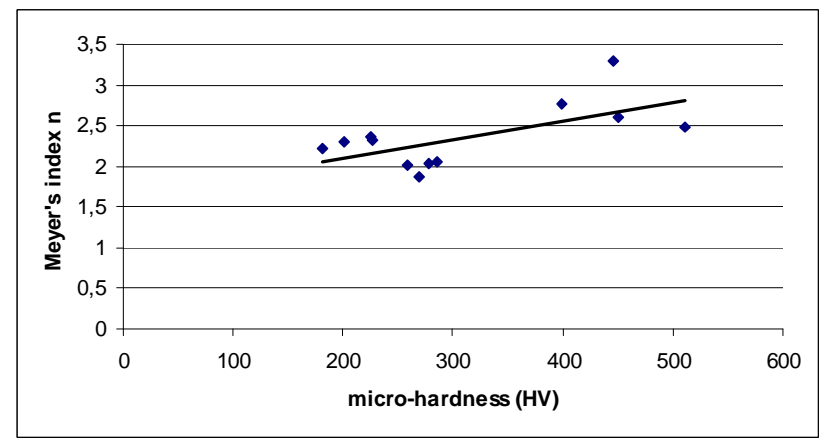

Fig. 8. The relationship between Meyer's index "n" and micro-hardness. 
The loads were divided into groups: A for $10 \div 30 \mathrm{~g}$, B for $40 \div 60 \mathrm{~g}$ and for $\mathrm{C} 70 \div 100 \mathrm{~g}$ in respect of micro-hardness and A for $5 \div 15 \mathrm{~kg}$, B for $20 \div 40 \mathrm{~kg}$ and $\mathrm{C}$ for $50 \div 120 \mathrm{~kg}$ in respect of macro-hardness. The index " $n$ " was calculated for particular groups. The index $n>$ 2 in group A for all micro-hardness calibrations $(n=2.5704$ in average). The group $B(n=$ 1.61508 in average $)$ and especially group $C(n=1.70473$ in average $)$ have normal ISE behavior despite of expectance (higher load should increase the tendency for behavior according to Kick's Law). The expected behavior was obtained for macro-hardness. The relationship between the load and the diagonals of indentation satisfies conditions of Kick's Law ( $\mathrm{n}=2.0504$ for group A, 1.99645 for B and 2.05105 for C). The relationship between load and dimensions of indentation for groups of the loads and CRMs are in Fig. 9.

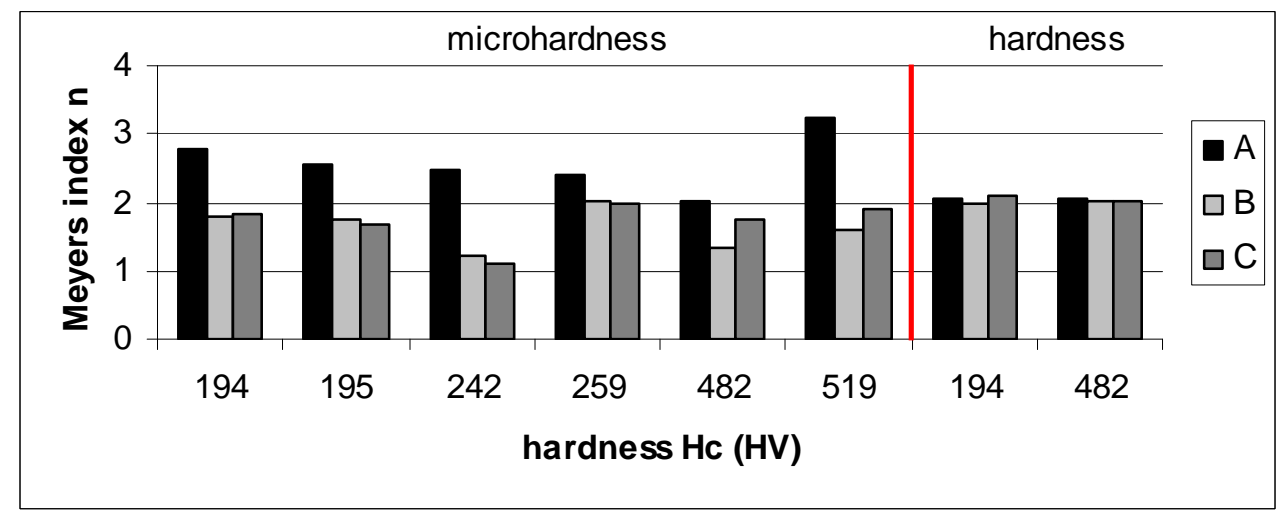

Fig. 9. Meyer's index “n” for individual groups of loads.

The relationship between Meyer's index " $n$ " and individual indices of capability is shown in Fig. 10 and "ndc" in Fig. 11. The capability of the measurement process increases (the value of \%GRR decreases, $r=0.8077$ ) with increasing " $\mathrm{n}$ " towards more reverse ISE behavior (and higher hardness). The value of "ndc" increases likewise.

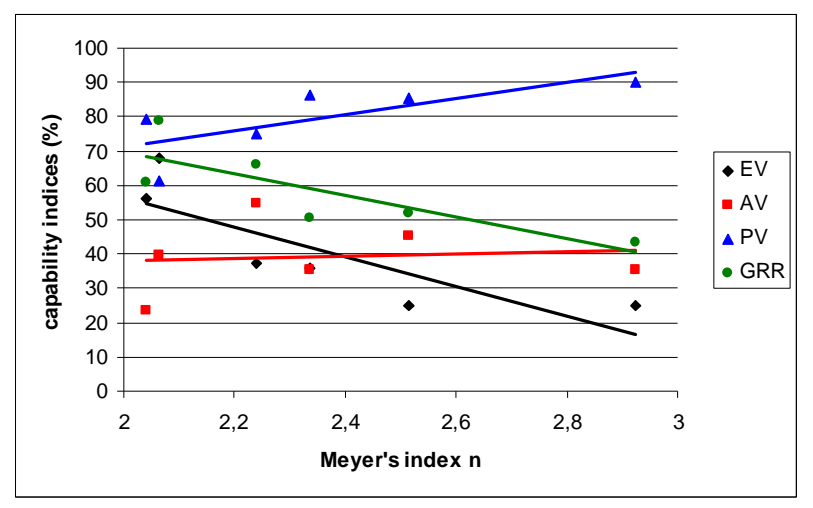

Fig. 10. The relationship between Meyer's index " $n$ " indices of capability.

\section{Conclusions}

1. The relationship between the load and micro-hardness in calibration of a micro-hardness tester cannot be explained by Kick's Law (the value of Meyer's index "n" differs from 2).

2. The conditions of Kick's Law are satisfied in macro-hardness calibration, the values of " $n$ " are close to 2 independently of the applied load. 
3. The micro-hardness increases with an increase of the load up to $30 \mathrm{~g}$; the reverse ISE behavior is typical for this interval of the loads, the equipment used and abovementioned conditions of measurement.

4. The influence of the load on the measured micro-hardness is statistically significant for a majority of calibrations.

5. The uncertainty decreases with an increase of the load and micro-hardness.

6. The quality (capability) of a micro-hardness measurement process on CRMs with more significant reverse ISE behavior (inversely proportional to \%GRR and proportional to "ndc") was higher.

7. The Z-score method confirmed a statistically significant influence of low loads on the value of the hardness.

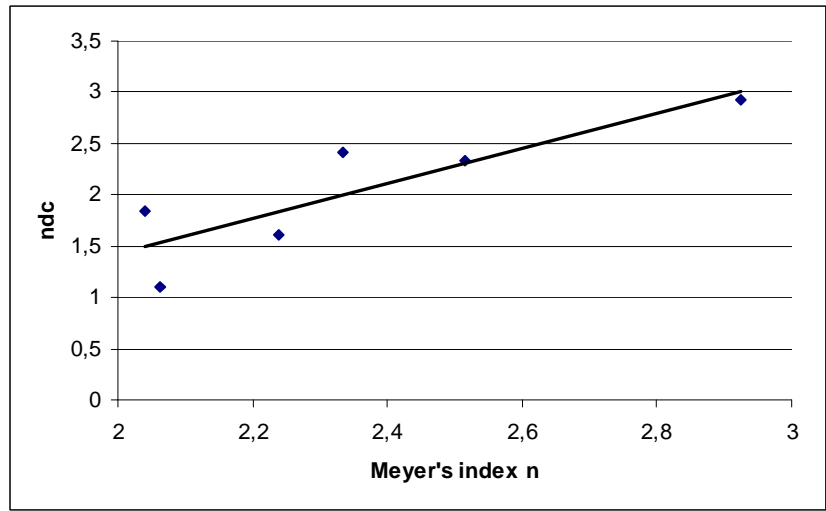

Fig. 11. The relationship between Meyer's index "n” and "ndc".

\section{Acknowledgements}

This work was supported by the Slovak Grant Agency for Science VEGA 1/0672/10.

\section{References}

[1] Swornowski, P. (2006). The influence of inaccuracy of calculating algorithms used in the CMMs on measurement results - final report. Metrology and Measurement Systems, 13(4), 433-446.

[2] Veles, P. (1985). Mechanical properties and testing of metals. Alfa/SNTL, 307-320. (in Slovak)

[3] Sangwal, K., Surowska, B., Błaziak, P. (2002). Analysis of the indentation size in the microhardness measurement of some cobalt-based alloys. Materials Chemistry and Physics, 77(2), 511-520.

[4] ISO 10 012:2003 Measurement management systems - Requirements for measurement processes and measuring equipment.

[5] STN EN ISO 6507-2:2005 Metallic materials. Vickers hardness test. Part 2: Verification and calibration of testing machines.

[6] STN EN ISO 6507-1:2005 Metallic materials. Vickers hardness test. Part 1: Test method.

[7] Adamczak, S. et al. (2011). Statistical validation of the method for measuring radius variations on the machine tool. Metrology and Measurement Systems, 18(1), 35-46.

[8] Measurement system s analysis (MSA). (2003). Reference manual. Third edition, 102-120.

[9] Methodical guidelines for accreditation. (1998). Proficiency testing schemes. MSA 0113-98, 32-34. (in Slovak).

[10] Tobolski, E. (2003). Uncertainty in Hardness testing. Advanced materials \& processes, 161(5), 25-26. 
[11] EA-10/16 EA Guidelines on the Estimation of Uncertainty in Hardness Measurements. (2004). Annex Guideline to the evaluation of the uncertainty of the Brinell and the Vickers measuring method.

[12] Dietrich, E. (2001) Es geht auch einfach. Messunsicherheit in Analogie zur Prüfmittelfähigkeit bestimmen. QZ Magazine, 46 (3), 264 - 265. (in German).

[13] Fotowicz, P. (2010). Systematic effect as a part of the coverage interval. Metrology and Measurement Systems, 17 (3), 439-446.

[14] Petrík, J., Palfy, P. (2010). The quality of Vickers hardness tester calibration. Journal of Engineering. Annals Faculty of Engineering Hunedoara, 8 (1), 63-66.

[15] Gong, J., Wu, J., Guan, Zh. (1999). Examination of the Indentation Size Effect in Low-load Vickers Hardness Testing of Ceramics. Journal of the European Ceramic Society, 19, 2625 - 2631.

[16] Sangwal, K., Hordyjewicz, M., Surowska, B. (2002). Microindentation hardness of $\mathrm{SrLaAlO}_{4}$ and $\mathrm{SrLaGaO}_{4}$ single crystals. Journal of Optoelectronics and Advanced Materials, 4(4), 875-882. 